\title{
A Documentation of Hepatitis Outbreak in Chittagong
}

\author{
Rajat Sanker Roy Biswas ${ }^{1 *}$ \\ Fahim UI Hasan ${ }^{2}$ \\ Aklima Sultana ${ }^{3}$ \\ Md Kamal Uddin ${ }^{4}$ \\ Debashis Chowdhury ${ }^{5}$ \\ Serajun Noor Rosy ${ }^{3}$ \\ Shaikh Md Hasan Mamun ${ }^{1}$
}

${ }^{1}$ Department of Medicine

Chattagram Maa-O-Shishu Hospital Medical College Chittagong, Bangladesh.

${ }^{2}$ Department of Community Medicine Chattagram Maa-O-Shishu Hospital Medical College Chittagong, Bangladesh.

${ }^{3}$ Department of Gynaecology and Obstetrics Chattagram Maa-O-Shishu Hospital Medical College Chittagong, Bangladesh.

${ }^{4}$ Department of Medicine

Bangabandhu Memorial Hospital (USTC)

Chittagong, Bangladesh.

${ }^{5}$ Department of Gastroenterology

Chattagram Maa-O-Shishu Hospital Medical College Chittagong, Bangladesh
*Correspondence to:

Rajat Sanker Roy Biswas

Assistant Professor

Department of Medicine

Chattagram Maa-O-Shishu Hospital Medical College

Chittagong, Bangladesh.

Mobile : +8801819808433

E-mal:rajatbiswas76@yahoo.com

www.banglajol.info/index.php/CMOSHMCJ

\begin{abstract}
Introduction: Hepatitis E Virus (HEV) causes outbreaks of jaundice and it is associated with morbidity and higher maternal mortality. There is a recent outbreak of hepatitis in the Chittagong city and present study is aimed to observe the clinical and serological trends along with outcome of hepatitis cases visiting two tertiary care hospitals Chittagong, Bangladesh. Methods: It was an observational study done in two tertiary care hospital of Chittagong in a period of 3 months (May, June \& July 2018) among 230 patients of hepatitis. After inclusion with written informed consent patients were introduced a questionnaire. Their demographic data, risk behaviors were noted, history related to hepatitis were recorded. Examination was done and evaluation regarding presence of hepatic encephalopathy at bed site was noted. Later serological findings were evaluated. After collection of all data it were compiled and analyzed by SPSS- 20. Results: Among 230 cases age group, gender and locality of the study patients were analyzed where younger age groups specially 21-30 years $114(49.6 \%)$ and $31-40$ years $38(16.5 \%)$ were the most affected group. Gender distribution was found mostly same. Halishahar area which is located in western part of the Chittagong city was found mostly affected 196(85.2\%). Use of water from WASA (Water and Sewerage Authority) supply was 168(73\%) and deep tubewel water was 56(24.3\%). Among them $80(34.8 \%)$ subjects do not boil water Anorexia (74.8\%) nausea (77.4\%) vomiting (83.5\%) history of fever $(89.6 \%)$ passage of dark color urine $(99.1 \%)$ and weakness $(97.4 \%)$ were some common presenting complaints. Family history of jaundice was found in $40.9 \%$ of cases. Among all 216(93.91\%) had clinical jaundice, 91(39.56\%) had right upper quadrant of the abdomen pain, 41(17.8\%) had hepatomegally, 14(6.1\%) had spleenomegally, $24(10.4 \%)$ had signs of hepatic failure and $34(14.8 \%)$ female were pregnant. Anti HEV was found positive in 164(71.3\%) cases, 12(5.2\%) were positive for anti HAV, $6(2.6 \%)$ were positive for HBsAg. None was found anti HCV positive. Among all $4(1.8 \%)$ cases died due to hepatic failure or multi-organ failure with AKI. All of them were pregnant. Two pregnant lady had missed abortion. Among all 11(4.7\%) cases loosed follow and 213(92.60\%) cases had uneventful recovery. Conclusion: This outbreak of HEV was of usual pattern of morbidity and mortality, and therefore points to water supply and sanitation issues.
\end{abstract}

Key words : Hepatitis; Hepatitis E; Outbreak; Chittagong.

\section{INTRODUCTION}

Viral hepatitis are common infectious disease in Bangladesh. Hepatitis A, B, C, and $\mathrm{E}$ are the common viruses responsible for it. Viral hepatitis constitutes huge burden to the health care delivery system and it has an economic impact in Bangladesh. Hepatitis E virus is the leading cause of acute hepatitis in this country. For chronic liver disease, hepatitis B virus is one of the main cause and its prevalence is $5-6 \%$ in our country and next to it is hepatitis $\mathrm{C}$ and its prevalence is $1 \%{ }^{1,2}$. 
In a common setting of the developing country with significant poverty and poor food and sanitation, not unexpectedly Bangladesh offers favorable conditions for nurturing Hepatitis E Virus (HEV) infection ${ }^{3}$. HEV infection occurs as seasonal, sporadic and non-seasonal HEV outbreaks with significant mortality have been reported from Bangladesh. HEV remains the leading cause of acute hepatitis and in pregnancy it is more fatal. It is also one of the rare cause of Acute Chronic Liver Failure (ACLF) in this country ${ }^{3}$. Most recent outbreak of hepatitis is observed in western part of Chittagong City for last 5 months. Chattagram Maa Shishu-O-General Hospital (CMSOGH) and Bangabandhu Memorial Hospital (BBMH) are two hospitals present around the focal outbreak. Maximum patients are admitted or visit the out patient department of these two centers for the management of hepatitis. So an observational study is designed to find out the clinic-pathological features of hepatitis among the affected community.

\section{MATERIALS AND METHODS}

It was an observational study done in two tertiary care hospital of Chittagong in a period of 3 months (May, June \& July 2018) among 230 patients of hepatitis. Case definition of hepatitis was patients visiting with history suggestive of hepatitis (Anorexia/nausea/vomiting/yellow eye/dark urine) with past history of short duration fever, if researchers clinically suspects the patients as a case of acute hepatitis in the background of history and examination and hospital admitted patients with clinically documented acute hepatitis biochemically of serologically. Patients unwilling to be included in the study and to do the blood tests were excluded. All patients were recruited as per the case definition of the hepatitis. A data collection form were used after informed written consent for collection of information. Demographic, clinical and laboratory data were collected from each patients. Examination was done and evaluation regarding presence of hepatic encephalopathy at bed site was noted. Hepatitis serology for HAV anti HAV, for HBV HBsAg, for HCV anti HCV and for HEV and anti HEV were done. After collection of all data it were compiled and analyzed by SPSS 20 .

\section{RESULTS}

Table 1 : Demography of the study patients

\begin{tabular}{llr} 
Parameters & & $\mathbf{n}(\%)$ \\
Age Group & $<20$ Years & $44(19.1 \%)$ \\
& 21-30 Years & $114(49.6 \%)$ \\
& 31-40 Years & $38(16.5 \%)$ \\
& 41-50 Years & $16(7.0 \%)$ \\
& 51-60 Years & $14(6.1 \%)$ \\
& $>60$ Years & $4(1.7 \%)$ \\
Gender & Male & $120(52.2 \%)$ \\
& Female & $110(47.8 \%)$ \\
Locality & Halishahar & $196(85.2 \%)$ \\
& Chittagong City (Other than Halishahar) & $24(10.4 \%)$ \\
& Outside Chittagong city & $10(4.3 \%)$ \\
Total & & $230(100.0 \%)$ \\
\hline
\end{tabular}

Table 1 revealed age group, gender and locality of the study patients where it was noted that younger age groups specially 21-30 years $114(49.6 \%)$ and $31-40$ years $38(16.5 \%)$ were the most affected group. Sex distribution was found similar. Halishahar area which is located in western part of the Chittagong city was found mostly affected 196(85.2\%)

Table 2 : Category of drinking water and practice of boiling water used in household

\begin{tabular}{llr} 
Parameters & & n (\%) \\
Type drinking water & WASA supply & $168(73.0 \%)$ \\
Deep tubewel & & $56(24.3 \%)$ \\
Shallow tubewell & & $6(2.6 \%)$ \\
Boiling of water & Yes & $150(65.2 \%)$ \\
& No & $80(34.8 \%)$ \\
& Total & $230(100.0 \%)$ \\
\hline
\end{tabular}

Table 2 revealed mostly used household water from WASA supply $168(73 \%)$. Some others were using deep tubewel water $56(24.3 \%)$. Among them 80(34.8\%) subjects do not boil water.

Table 3 : Presenting features

$$
\text { Parameters }
$$

Anorexia

Nausea

Vomiting

Presence of foul smell in taking food

$\mathrm{H} / \mathrm{O}$ fever

Past history of jaundice

Family history of jaundice

Abdominal pain

Passage of dark colored urine

Constipation

Weakness

Itching of the body

Comorbid conditions

(DM, HTN, IHD, CLD etc) $172(74.8 \%)$ $178(77.4 \%)$ $192(83.5 \%)$ $158(68.7 \%)$ $206(89.6 \%)$ $56(24.3 \%)$ $94(40.9 \%)$ $140(60.9 \%)$ $228(99.1 \%)$ $141(61.3 \%)$ 224(97.4\%) $117(50.9 \%)$

Table 3 explored anorexia (74.8\%) Nausea (77.4\%) Vomiting $(83.5 \%)$ History of fever $(89.6 \%)$ passage of dark color urine $(99.1 \%)$ and weakness $(97.4 \%)$ were some common presenting complaints. Family history of jaundice was found in $40.9 \%$ of cases.

Table 4 : Physical features

$\begin{array}{lr}\text { Parameters } & \text { n (\%) } \\ \text { Jaundice } & 216(93.91 \%) \\ \text { RUQ tenderness } & 91(39.56 \%) \\ \text { Hepatomegaly } & 41(17.8 \%) \\ \text { Spleenomegaly } & 14(6.1 \%) \\ \text { Presence of signs of hepatic failure } & 24(10.4 \%) \\ \text { Number of pregnant women } & 34(14.8 \%)\end{array}$

Table 4 describing examination findings where 216(93.91\%) had clinical jaundice, 91(39.56\%) had right upper quadrant of the abdomen pain, $41(17.8 \%)$ had hepatomegaly, $14(6.1 \%)$ had spleenomegaly, 24(10.4\%) had signs of hepatic failure and $34(14.8 \%)$ female were pregnant. 
Table 5 : Hepatitis sero profile

\begin{tabular}{llr} 
Parameters & & $\mathbf{n}(\%)$ \\
Anti HAV & Positive & $12(5.2 \%)$ \\
& Negative & $64(27.8 \%)$ \\
& Not done & $15467.0 \%)$ \\
Anti HEV & Positive & $164(71.3 \%)$ \\
& Negative & $23(10.0 \%)$ \\
HBsAg & Not done & $43(18.7 \%)$ \\
& Positive & $6(2.6 \%)$ \\
& Negative & $128(55.7 \%)$ \\
Anti HCV & Not done & $96(41.7 \%)$ \\
& Negative & $34(14.8 \%)$ \\
& Not done & $196(85.2 \%)$ \\
\hline
\end{tabular}

Table 5 explored, among 187 test for anti HEV done, 164(71.3\%) were positive for anti HEV, 12(5.2\%) were positive for anti HAV, 6(2.6\%) were positive for HBsAg. None was found anti $\mathrm{HCV}$ positive among 34 tests done.

Table 6 : Outcome

\begin{tabular}{lr} 
Outcome & $\mathbf{n}(\%)$ \\
Death due to hepatic failure & $2(0.9 \%)$ \\
Death due to MOF with AKI & $2(0.9 \%)$ \\
Missed abortion & $2(0.9 \%)$ \\
Uneventful recovery & $213(92 \%)$ \\
Loosed follow & $11(4.7 \%)$ \\
\hline
\end{tabular}

Table 6 showing $4(1.8 \%)$ cases died due to hepatic failure or multi-organ failure with AKI. All of them were pregnant. Two pregnant lady had missed abortion. Among all 11(4.7\%) cases loosed follow and 213(92.60\%) cases had uneventful recovery.

\section{DISCUSSION}

In this study among 230 cases of acute hepatitis, 187 patients were tested for hepatitis sero profiles. Among then 164(71.3\%) were positive for anti HEV. Also 12(5.2\%) were found positive for anti HAV, 6(2.6\%) were found positive for $\mathrm{HBsAg}$. None was found anti HCV positive. Acute hepatitis is seen sporadically round the year in Bangladesh ${ }^{3}$. Outbreaks of acute infectious hepatitis have been attributed to Hepatitis E Virus (HEV) since the $1950 \mathrm{~s}^{4}$. Large HEV outbreaks reported from Asia and Africa have been associated with fecally contaminated drinking water. ${ }^{5-9}$ Although persons with HEV disease usually fully recover, clinical studies report that pregnant women who become infected with HEV, and their newborns, often die and this has also been observed during HEV outbreaks ${ }^{10,11}$. In our study $4(1.8 \%)$ case fatality occurred due to hepatic failure or multi-organ failure with AKI. All of them were pregnant. Two pregnant lady had missed abortion. There is no surveillance for HEV in Bangladesh,although limited studies suggest that it is the commonest cause of fulminant hepatitis ${ }^{12}$.
Bangladesh is considered to be a country where hepatitis A infection is hyperendemic with $100 \%$ of children $\leq 6$ years of age exposed and immune to $\mathrm{HAV}^{13}$. As a South East Asian country Bangladesh is considered endemic for hepatitis B virus (HBV) infection ${ }^{14}$. In the general population, HEV carries alow mortality of $0.5-4 \%$. However, this figure approaches $>75 \%$ in developing countries, such as Bangladesh, in the second/third trimester of pregnancy and in patients with fulminant hepaticfailure ${ }^{3}$. Hepatitis E virus was called a leading cause of acute-on-chronic liver disease in a retrospective study conducted by Mahtab et al In Bangladesh, information about prevalence of $\mathrm{HBV}$ infection is very meager and there is no available data on HDV infection ${ }^{3}$.

In this study we found that younger age groups specially 2130 years $114(49.6 \%)$ and $31-40$ years $38(16.5 \%)$ were the most affected group. Gender distribution was found same. Halishahar area which is located in western part of the Chittagong city was found mostly affected 196(85.2\%). WASA supply was the main household source of water in $168(73 \%)$ cases and others were using deep tubewel water 56(24.3\%). Among them 80(34.8\%) subjects do not boil water. This is a large outbreak of hepatitis in a densely populated area like Halishahar, low to middle income, urban community was due to HEV. Evidence from this investigation suggests that it might be spread through fecal contamination of the municipal water system. Although the highest risk of illness was among men who worked outside the home, most deaths occurred in women with confirmed pregnancies was found and casual relation was unconfirmed. Drinking from the municipal supply water outside the home was highly associated with HEV disease in a dose response manner.

In our study anorexia (74.8\%), nausea (77.4\%), vomiting $(83.5 \%)$ history of fever $(89.6 \%)$ passage of dark color urine (99.1\%) itching (50.4\%) and weakness (97.4\%) were some common presenting complaints. Family history of jaundice was found in $40.9 \%$ of cases. Regarding examination findings $216(93.91 \%)$ had clinical jaundice, $91(39.56 \%)$ had right upper quadrant of the abdomen pain, 41(17.8\%) had hepatomegaly, $14(6.1 \%)$ had spleenomegaly, 24(10.4\%) had signs of hepatic failure and 34(14.8\%) female were pregnant.In a study done by Batta found the sign and symptoms developed by the hepatitis affected patients were classical sign and symptoms ${ }^{15}$. They found Jaundice (28.57\%) and weight loss $(28.57 \%)$ were most common with loss of appetite $(10.71 \%)$. It was an interesting observation that $5.71 \%$ of patients reported to have itchy skin. Itchiness is developed in particularly hepatitis A patients as a result of cholestasis. These are some common history and examination findings among the patients of hepatitis and these are as expected.

\section{CONCLUSION}

HEV induced hepatitis is a preventable disease with provision of clean drinking water; although effective vaccines have been 
developed but none are currently available in our country ${ }^{16}$. Fatality was low among the patients but pregnant mothers were the main victim found in this study. Interventions to prevent $\mathrm{HEV}$ in the low-income countries like Bangladesh where HEV is endemic will require redistribution of scarce health resources, pure water supply and appropriate sewerage systems. Given that maternal mortality is a painful feature of HEV outbreaks, existing maternal health programs in HEV prone country like Bangladesh needs up-gradation with proper care.

\section{DISCLOSER}

All the authors declared no competing interest.

\section{REFERENCES}

1. Al-Mahtab M. Past, Present, and Future of Viral Hepatitis in Bangladesh. Euroasian J Hepato-Gastroenterol. 2016;6(1):43-44.

2. Mahtab MA, Rahman S, Foster G, Khan M, Karim MF, Solaiman S, Afroz S. Epidemiology of hepatitis B VIRUS in Bangladeshi general population. Hepatobiliary Pancreat Dis Int. 2008;7(6):595-600.

3. Mahtab MA, Rahman S, Khan M, Karim MF. HEV infection as an aetiologic factor for acute hepatitis: Experience from a tertiary hospital in Bangladesh. J Health PopulNutr. 2009 ;27(1):14-19.

4. Labrique AB, Thomas DL, Stoszek SK, Nelson KE. Hepatitis E: An emerging infectious disease. Epidemiol Rev. 1999; 21:162-179.

5. Rai RR, Nijhawan S, Mathur A, Sharma MP, Udawat HP, Singh N. Seroepidemiology and role of polymerase chain reaction to detect viremia in an epidemic of hepatitis E in western India. Trop Gastroenterol. 2008; 29:202-206.

6. Sailaja B, Murhekar MV, Hutin YJ et al. Outbreak of waterborne hepatitis E in Hyderabad, India, 2005. Epidemiol Infect. 2009; 137:234-240.

7. Bile $\mathrm{K}$, Isse $\mathrm{A}$, Mohamud $\mathrm{O}$ et al. Contrasting roles of rivers and wells as sources of drinking water on attack and fatality rates in a hepatitis E epidemic in Somalia. Am J Trop Med Hyg. 1994; 51:466-474.

8. Maila HT, Bowyer SM, Swanepoel R. Identification of a new strain of hepatitis E virus from an outbreak in Namibia in 1995. J Gen Virol. 2004; 85(1):89-95.

9. Escriba JM, Nakoune E, Recio C et al. Hepatitis E, Central African Republic. Emerg Infect Dis. 2008; 14:681-683.

10. Bista BK, Rana A. Acute hepatitis E in pregnancy—study of 16 cases. J Nepal Med Assoc. 2006; 45:182-185.

11. Hamid SS, Jafri SM, Khan $\mathrm{H}$ et al. Fulminanthepatic failure in pregnant women: acute fatty liver or acute viral hepatitis? J Hepatol. $1996 ; 25: 20-27$.

12. Sheikh A, Sugitani M, Kinukawa $\mathrm{N}$ et al. Hepatitis $\mathrm{E}$ virus infection in fulminant hepatitis patients and an apparently health population in Bangladesh. Am J Med Hyg. 2002; 66:721-724.

13. Saha S.K, Saha S, Shakur S, Hanif M, Habib M.A, DattaS. K, Bock H.L. Community-based cross-sectional seroprevalence study ofhepatitis A in Bangladesh. World J Gastroenterol. 2009; 15(39): 4932-4937.

14. Chowdhury B.O, Ahamad M.S.U, Farooque A.H.M.O, Rahman A.J.E.N. Study on association of Hepatocellular Carcinoma with Hepatitis B Virus Infection: Bangladesh Perspective. Journal of Chittagong Medical College Teachers' Association. 2009; 20(1):31-33.

15. Batta A. Viral hepatitis and enzyme study. Int J Cur Bio Med Sci. 2011; 1(2): 41-43.

16. Zhang J, Liu CB, Li RC et al. Randomized-controlled phase II clinical trial of a bacterially expressed recombinant hepatitis $\mathrm{E}$ vaccine. Vaccine. 2009; 27:1869-1874 